\title{
Drug Utilization Analysis of Anticoagulant and Antiplatelet Drugs in Cardiology Department of a Tertiary Care Hospital
}

\author{
Sonal Vyas ${ }^{1}$, Wandeep Dagar ${ }^{1}$, Meenakshi Dhanawat ${ }^{2}$,, Sajaad Manzoor ${ }^{3}$, Sumeet Gupta ${ }^{4}$, Rina Das ${ }^{2}$, Dinesh Kumar Mehta ${ }^{2}$ \\ 'Department of Pharmacy Practice, MM College of Pharmacy, MM University (Deemed to be University), Mullana, Ambala, Haryana, INDIA. \\ 2Department of Pharmaceutical Chemistry, MM College of Pharmacy, MM University (Deemed to be University), Mullana, Ambala, Haryana, INDIA. \\ ${ }^{3}$ Department of Cardiology, MM. Institute of Medical Sciences and Research, MM University (Deemed to be University), Mullana, Ambala, Haryana, INDIA. \\ ${ }^{4}$ Department of Pharmacology, MM College of Pharmacy, MM University (Deemed to be University), Mullana, Ambala, Haryana, INDIA.
}

\begin{abstract}
Background: The current study was planned to estimate the usage of antiplatelet drugs and anticoagulant drugs patients in the teaching hospital. Methods: The records were composed through the Cardiology ward / Cardiac care unit (CCU) on regular basis after receiving agreement from the Institutional Ethics Committee (IEC). The documents pooling layout was generated and validated by giving inclination to drugs used by Coronary artery disease (CAD), Ischemic heart disease (IHD), Angina pectoris, Arterial fibrillation. Data of patient's identical inclusion criteria were noted. Results: An overall of 210 patients was included in the study giving an overview of the characteristics of the patients and prescriptions. In this study, the total number of male patients was found to be 118 , and the number of female patients was 92 . Coronary artery disease was observed to be more common in males $(56.2 \%)$ than in females $(43.8 \%)$. A total of 210 patients were taken for the study and patients were categorized according to their age group and gender. Conclusion: It was concluded that drug utilization of antiplatelet and anticoagulant drugs was $92.8 \%$ and
\end{abstract}

$63.80 \%$ respectively achieved in the tertiary care hospital in Northern India Jan-June 2021. Aspirin and Ticagrelor were the frequently used antiplatelet drugs whereas Heparin and Enoxaparin were the most used anticoagulant drugs in MMIMSR, Ambala. This study gives an idea for conducting Drug utilization review on antiplatelet and anticoagulants drugs with improved and better understanding.

Key words: Drug utilization review, Anticoagulant, Antiplatelet, Cardiovascular disease, Single-dual-triple antiplatelet therapy, Single dual anticoagulant therapy, Antiplatelet and anticoagulant therapy.

Correspondence

Dr. Meenakshi Dhanawat,

Associate Professor, MM College of Pharmacy, MM University (Deemed to be University), Mullana, Ambala-133207 Haryana, INDIA.

Email id: meenakshi.itbhu@gmail.com

DOI: 10.5530/jyp.2022.14.23

\section{INTRODUCTION}

In emergent nations, there is an unseemly and inadequate utilization of medication which is usually found in medical services frameworks all through the world. Medication Utilization Review (DUR) is a planned exertion by a doctor and drug specialist to surety the ideal result for a patient. DUR should be possible tentatively by the drug specialist while the medication is being conveyed or reflectively by HMSA by investigating claims information and different records for usage designs. The objective of DUR are: Ceaselessly assess and guarantee that ideal medication treatment results are accomplished, continuously improve patient consistency, diminish improper medication use and related hospitalization/office visits, Decrease antagonistic impacts of cooperations of medication use. Medication Utilization contemplates fill in as a scaffold between various regions like Pharmacoeconomics, pharmacovigilance, and proof-based medication, normal medication use, Pharmacogenetics. ${ }^{1}$

Cardiovascular disease (CVD) is definite by the World Health Organization (WHO) as a team of the condition of the coronary heart and blood vessels. This is the utmost severe and communal disease within the world. CVD situation embraces Coronary heart disease (CHD), stroke, cerebrovascular disease, hypertension, peripheral artery disease, rheumatic heart disease, congenital coronary heart disease and coronary failure. ${ }^{2,3}$

Coronary artery disease has carried out wide-ranging in India. Execution to the forecasts of the National Commission and Macroeconomics and Health, Government of India, the ordinary no. of coronary artery

disorder (CAD) patients in India at the flip of the century was once thirty million (5.3\% of the adult population) which may upward shove to extra than sixty million (7.6\%) through the 12 months 2015 . The annual facts range of deaths from CVD in India is probable to extend from 2.26 million (1990) to 4.77 million (2020). ${ }^{4}$

Antiplatelet treatment is significant in therapeutic action for anticipation of CHD and stroke. Dependent on the sign, the period of antithrombotic single rehabilitation or double therapy is different. Antithrombotic therapy is discovered to stop the reappearance of a cardiovascular episode, however, prolonged time of double antiplatelet therapy (DAPT) accompanying with improved threat of bleeding. Furthermore, the antiplatelet medicine itself is widely wide-spread to accomplice with unfavourable activities like guts and non-gastrointestinal haemorrhage, intracranial outflow, and hypersensitive reactions. Thus, it's peaks to the impulsive withdrawal of antithrombotic treatment which later occurs with a bigger threat of the cardiovascular incident afterward antithrombotic termination. Anticoagulants are medicines that are generally denoted as blood thinners and these are endorsed in clinical settings to treat hospitalized sufferers like acute and deep venous thromboembolism (VTE), unstable angina, atrial fibrillation. ${ }^{5}$ CAD, CVD, Peripheral artery disease, Rheumatic heart disease (RHD) and protect coronary arteries from blockage and in a cardiac protruding procedure. Anticoagulants are extremely recommended in cardiac and neuro units. For moreover forty years the only anticoagulants existing to clinicians are Coumarins and unfractionated Heparin (UFH). ${ }^{6}$

This is an open access article distributed under the terms of the Creative Commons Attribution-NonCommercial-ShareAlike 4.0 License, which allows others to remix, tweak, and build upon the work non-commercially, as long as the author is credited and the new creations are licensed under the identical terms. 
With the easiness of dermal direction management and inhibition of thrombus by Unfractionated Heparins and Coumarins are possibly now switched throughout earlier era by Enoxaparin and Dalteparin which are low molecular weight heparins. ${ }^{7}$ In non-valvular atrial fibrillation to inhibit congenital occlusion and stroke Dabigatran etiolate a direct antithrombin was permitted by Food Drug Administration (FDA) in the year 2015 under trademark name Pradaxa. ${ }^{4}$ In 2011 Rivaroxaban under trademark name Xarelta was permitted as the first factor Xa inhibitor specified orally preferable for sanitation of venous thrombosis (VT) in patients undertaking popliteal and pelvis replacement operation. ${ }^{8}$ FDA has accepted a modern anticoagulant named Rivaroxaban specified for pulmonary occlusion (PE) and deep vein thrombo embolism (DVTE) in the year 2012. ${ }^{9}$

In malice of comprehensive deviations in the occurrence of cardiovascular risk features through various areas, CVD has appeared as the foremost reason for decease in all parts of India, comprising underprivileged states and pastoral regions. The development of this outburst depends on the socioeconomic inclines, tobacco use, low fruit, and vegetable consumption, poor acquiescence have become more widespread amid those from lower socioeconomic circumstances leading to worse results. However, non-modifiable risk aspects cannot be altered, modifiable risk aspects can be improved through clinical involvement to stop further obstacles. ${ }^{10}$

To expand the sick person circumstance because of drug medication and interfering drug utilization assessment want to be studied in the hospital. ${ }^{11}$ In patients examined with CAD, Angina pectoris, Ischemic heart disease (IHD), Atrial fibrillation (AF), Myocardial infarction (MI), hypertension use of dissimilar cardiac substitute drugs is added to treat as first-line management. The consequent drugs like inotropes, vasopressors, antihypertensive, antiplatelet, lipid-lowering, and anticoagulants are regularly used in the hospital for the controlling of $\mathrm{CAD}$, Angina pectoris, IHD, AF, MI, hypertension. The current study was planned to estimate the use of antiplatelet drugs and anticoagulant patients in training hospitals. ${ }^{12,13}$

\section{Methodology}

A prospective observational study was conducted on 210 patients for 6 months from January 2021-June 2021to evaluate Drug Utilization pattern of Anticoagulant and Antiplatelet Drugs. It was observed that different classes of Anticoagulant and Antiplatelet Drugs were prescribed in cardiology department. The protocol of the study was approved by Institutional Ethics Committee (IEC) at Maharishi Markandeshwar Institute of Medical Sciences and Research (MMIMSR), Mullana having ethical clearance number: 1874 .

A data entry format was specially designed which was used to enter patient demographic data (name, age, gender, address), date of admission, date of discharge, patient social history, medication history, past medical history, diagnosis, type of Anticoagulant and Antiplatelet Drugs prescribed, dose, side effects etc. Finally, the results were analyzed using descriptive statistical methods and reported to concerned departments. The records series structure used to be created and authenticated via giving choice to medicinal drugs used by using CAD, IHD, Angina pectoris, Arterial fibrillation. Data of patients matching inclusion standards have been recorded.

\section{Inclusion criteria}

Patients who were admitted in the Cardiology ward who are prescribed anticoagulants or anti-platelet drugs and are of age between 18 to 80 years and patients willing to participate are included in the study.

\section{Exclusion criteria}

Patients below 18 years of age and above 80 years of age, pregnant and lactation women, psychiatric patients, patient under critical condition and requiring critical care stay, patients having Tuberculosis and Diabetes Mellitus, patients suffering with other than respiratory tract infections and those who are on Chemotherapy, patients not willing to sign inform consent form were excluded from the study.

\section{RESULTS}

All subjects satisfy the inclusion and exclusion criteria were included as the study population. A total of 210 patients were included in the study which were categorized according to their age group and gender. The total number of 118 male patients (56.2\%) and 92 female patients (43.8\%) were there. According to age group distribution 3 subjects were in age group of 20-30 years, 16 subjects were in age group of 30-39 years, 32 subjects were in age group of 40-49 years, 48 subjects were in age group of 50-59 years, 61 subjects were in age group of 60-69 years, 50 subjects were in age group more than 70 years. The mean age of population was 58.8 (12.09) (Mean \pm SD). The numbers of the patient with age group are given in Table 1. Subjects were categorized according to patients having only CAD and those having CAD with other co-morbidities. Out of 210 patients 82 were diagnosed only with CAD that is $39.04 \%$. Among those $20 \%$ were Male $19.04 \%$ were female patient. Whereas, 128 patients were found to be with $\mathrm{CAD}$ and other co-morbidities i.e. $60.95 \%$, comprises of $36.19 \%$ male and $24.76 \%$ female patients are shown in Table 2 .

According to the type antiplatelet and anticoagulant prescribed, aspirin was prescribed to 159 patients $(75.71 \%)$, ticagrelor to 125 patients (59.52\%), Clopidogrel to 57 patients (27.14\%), tirofiban to 65 patients $(32.90 \%)$, Heparin to 72 patients $(34.28 \%)$, Enoxaparin to 60 patients (29\%) and Rivaroxaban was prescribed to 2 patients $(0.90 \%)$.

Distribution according to number of antiplatelet and anticoagulant prescriptions, single antiplatelet therapy was given to 54 patients $(25.7 \%)$,

Table 1: Distribution of patients based on gender and age group.

\begin{tabular}{cc}
\hline Variables & No. of Patients (\%) \\
\hline \multicolumn{3}{c}{ Gender } \\
\hline Female & $118(56.20 \%)$ \\
$92(43.80 \%)$ \\
\hline $20-29$ & Age (Years) \\
$30-39$ & $3(1 \%)$ \\
$40-49$ & $16(8 \%)$ \\
$50-59$ & $32(15 \%)$ \\
$60-69$ & $48(23 \%)$ \\
$70-80$ & $61(29 \%)$ \\
\hline
\end{tabular}

Table 2: Distribution of patients based on gender in CAD and Distribution of patients on gender in patient with CAD and other comorbidities.

\begin{tabular}{ccc}
\hline Type & Gender & No. of Patients (\%) \\
\hline \multirow{2}{*}{ CAD } & Male & $42(20 \%)$ \\
& Female & $40(19.04 \%)$ \\
CAD + other comorbidities & Male & $76(36.19 \%)$ \\
& Female & $52(24.76 \%)$ \\
\hline
\end{tabular}


Vyas, et al.: Drug Utilization Analysis of Anticoagulant and Antiplatelet

\begin{tabular}{|c|c|c|c|c|c|c|c|}
\hline Age & $\begin{array}{l}\text { No. of } \\
\text { Patients }\end{array}$ & $\begin{array}{c}\text { Single } \\
\text { Antiplatelet }\end{array}$ & $\begin{array}{c}\text { Dual } \\
\text { Antiplatelet }\end{array}$ & Triple Antiplatelet & $\begin{array}{c}\text { Single } \\
\text { Anticoagulant }\end{array}$ & $\begin{array}{c}\text { Dual } \\
\text { Antiplatelet }\end{array}$ & $\begin{array}{l}\text { Patients with Antiplatelet } \\
\text { and Anticoagulant }\end{array}$ \\
\hline $20-29$ & 3 & 1 & 2 & 0 & 0 & 0 & 0 \\
\hline $30-39$ & 16 & 9 & 8 & 0 & 6 & 1 & 8 \\
\hline $40-49$ & 32 & 8 & 20 & 4 & 12 & 2 & 12 \\
\hline $50-59$ & 48 & 15 & 24 & 12 & 20 & 4 & 24 \\
\hline $60-69$ & 61 & 10 & 32 & 20 & 30 & 4 & 32 \\
\hline $70-80$ & 50 & 11 & 24 & 14 & 32 & 5 & 34 \\
\hline Total no. of Patients (\%) & 210 & $54(25.70 \%)$ & $110(52.30 \%)$ & $50(23.80 \%)$ & $100(47.60 \%)$ & $16(7.60 \%)$ & $110(52.30 \%)$ \\
\hline
\end{tabular}

double antiplatelet therapy was given to 110 patients $(52.3 \%)$, triple antiplatelet therapy was given to 50 patients $(23.8 \%)$, single anticoagulant therapy was given to 100 patients $(47.6 \%)$, double anticoagulant therapy was given to 16 patients $(7.6 \%)$ and anticoagulant with antiplatelet therapy was given to 110 patients $(52.3 \%)$ are given in Table 3 .

Patients were also categorized according to their concomitant illness. Statin therapy was given to 156 patients $(74.28 \%)$, CAD with diabetes was (5.7\%), with hypertension (68\%), and with Angina was $7.60 \%$. The prevalence of CAD with hypertension was more.

\section{DISCUSSION}

CAD is a leading non-communicable disease in case of high morbidity and mortality in the world. Many people lost their life due to CAD than any other disease. According to statisticians in western countries, the death rate is $23 \%$ previously the era of 70 years and also in India, this character is $50 \%$. The annual number of deaths by CAD increase from 2.26 million (1990) to 4.77 million (2020). By 2030, it is estimated that more than 3.6 million people will die from CAD (7).

The CAD treatment involves the use of various categories of drugs like anticoagulants, antiplatelet, antianginal, beta-blockers, ACE inhibitors, ARBs, CCBs, diuretics, etc. There are many screening and management to evaluate the strategies for CAD in many big countries but in India, these strategies are not fully implemented yet. ${ }^{14} \mathrm{~A}$ randomized controlled study suggests that usage of aspirin, ACE inhibitors, Beta antagonist, Statins can be useful in all patients with indicative enduring stable angina or MI and coronary evade surgery for inferior anticipation of MI, stroke, or passing. ${ }^{15-17}$

From this, a hypothesis has been invented that collectively using these mediators might decrease the extensive period threat of cardiovascular happenings as well as death. However actual impact will be dependent on the matter of which are being practiced in the hospital. ${ }^{18}$ In this study, we observed that mostly two categories of antiplatelet drugs were prescribed Aspirin and Ticagrelor. The rate of antiplatelet drugs given for the CAD remained found to be higher in men than for a woman. The chance of CVD is more in India due to sign of numerous diseases through the Indian people. Intravenous heparin was recommended as a prophylaxis treatment in inpatients of cardiology departments followed by Enoxaparin. The patient's age between $50-80$ was most affected with CAD. In this study, we also observed that mostly single treatment of anticoagulant was used such as Heparin. The Patient's age between 40-80 was mostly prescribed anticoagulant drug. The various study held that the occurrence of CAD is developed in the sixth decade of life of humans when parallel to further age of the group. ${ }^{19}$

It used to be detected that the Aspirin, Ticagrelor, Heparin and Atorvastatin used to be most commonly used drug for the CAD sufferers in this medical institution. Drug Use in CAD associated with DM and
HTN shows that Aspirin along with Ticagrelor, Heparin, Atorvastatin, Antidiabetic drug and Beta-blocker, may be beneficial over other drugs used alone. ${ }^{20}$ In the single study is described that Aspirin was recommended in low dose for CAD management and anticipation. ${ }^{21}$ In this study patients were prescribed with single antiplatelet was (25.7\%), Double Antiplatelet was (52.3\%), Triple Antiplatelet was (23.8\%), Single Anticoagulant was (47.6\%), Double Anticoagulant therapy was (7.6\%) and patients with Anticoagulant and Antiplatelet therapy was given $(52.3 \%)$.

Among 210 patients another cardiovascular drug used concomitantly was beta-blocker $68.57 \%$ ACE inhibitors $37.61 \%$, diuretics $35.71 \%$, nitrates $7.60 \%$ and statin $74.28 \%$. All this concomitant medication was prescribed in the $30-80$ years age group of patients. The improved condition was observed during the followed-up data. The present result of the study revealed that appropriate drug consumption of the antiplatelet drugs in the certain training hospital. Among the overall 210 patients, 195 were prescribed with antiplatelet and 134 patients were prescribed with anticoagulant drugs. The $92.8 \%$ drug utilization of antiplatelet drugs and $63.80 \%$ drug utilization of anticoagulant drugs were observed in this study. Same effects have been discovered in different research like in a tertiary care medical institution Kolkata suggests 90\% drug utilization pills and different cardiovascular drug was once perceived. ${ }^{22}$

\section{Inference}

In our study we establish common drug interactions Example:- Heparin with Aspirin, Heparin with Clopidogrel, Heparin with Rivaroxaban, Enoxaparin with Heparin, Heparin with Tirofiban, Aspirin with Ticagrelor, Aspirin with Clopidogrel, but these interactions were managed by the physician with the help of time management of drugs.

We establish that $92.8 \%$ drug utilization of antiplatelet and $63.80 \%$ for anticoagulants were achieved in the tertiary care hospital in Northern India January 2021- June 2021. Aspirin and Ticagrelor were the commonly used antiplatelet drugs. Heparin and Enoxaparin were the most used anticoagulant drugs in this hospital. This study gives an idea for conducting DUR on antiplatelet and anticoagulants drugs with improved and better understanding.

\section{ACKNOWLEDGEMENT}

The authors are highly acknowledged to the M.M. College of Pharmacy, MM (Deemed to be University) and Department of Cardiology, M.M.I.M.S.R, MM (Deemed to be University), Mullana, Ambala, Haryana, India for Providing support to carry out the research work.

\section{CONFLICT OF INTEREST}

The authors declare that there is no conflict of interest. 


\section{REFERENCES}

1. Jain $S$, Upadhyaya $P$, Goyal J, Kumar $A$, Jain $P$, Seth $V$, et al. A systematic review of prescription pattern monitoring studies and their effectiveness in promoting rational use of medicines. Perspect Clin Res. 2015;6(2):86-90. doi: 10.4103/2229-3485.154005, PMID 25878953.

2. Najeeb Q, Hamid S, Khan AH. Novel biomarkers in assessing cardiovascular status in acute myocardial infarction. J Cardiovasc Dis Res. 2014;5(4):22-7. doi: 10.5530/jcdr.2014.4.5

3. Thygesen K, Alpert JS, Jaffe AS, Simoons ML, Chaitman BR, White HD, et al. Third universal definition of myocardial infarction. J Am Coll Cardiol. 2012;60(16):1581-98. doi: 10.1016/j.jacc.2012.08.001, PMID 22958960.

4. Pradaxa. Ridgefield, CT: Boehringer Ingelheim Pharmaceuticals, Inc; 2012.

5. Braunwald E, Antman EM, Beasley JW, Califf RM, Cheitlin MD, Hochman JS, et al. American College of Cardiology, American Heart Association. Committee on the Management of Patients with Unstable Angina. ACC/AHA 2002 guideline update for the management of patients with unstable angina and non-ST-segment elevation myocardial infarction-summary article: A report of the American College of Cardiology/American Heart Association task force on practice guidelines (Committee on the Management of Patients With Unstable Angina). J Am Coll Cardiol. 2002;40(7):1366-74. doi: 10.1016/s07351097(02)02336-7, PMID 12383588.

6. Hirsh J, Fuster V. Guide to anticoagulant therapy. Part 2: Oral anticoagulants. American Heart Association. Circulation. 1994;89(3):1469-80. doi: 10.1161/01. cir.89.3.1469, PMID 8124830.

7. Groce J. Anticoagulation management strategies, guide for community pharmacist. Univ Tenn Adv Stud Pharm. 2007;4;Suppl 9:247-52.

8. Xarelto. Titusville, NJ. Janssen Pharmaceuticals, Inc; 2012.

9. FDA expands use of Xarelto to treat, reduce recurrence of blood clots. Food and Drug Administration. p. 2012; 6; 2013. Available from: http://www.fda.gov/ NewsEvents/Newsroom/PressAnnouncements [cited 2/2/2022].

10. Fahimi F, Baniasadi S, Behzadniac N, Varahrama F, Tabatabaie LG. Enoxaparin utilization evaluation: An observational prospective study in medical inpatients. Iran J Pharm Res. 2008;7(1):77-82.

11. WHO; 2014. Available from: http://apps.who.int/medicinedocs/en/d/Js4876e [cited 2/2/2022].

12. John LJ, Devi P, Guido S. Utilization of antihypertensive medications among the critically ill patients. RJPBCS. 2012;3(3):650-4.

13. Prabhakaran D, Jeemon P, Roy A. Cardiovascular Diseases in India: Current Epidemiology and Future Directions. Circulation. 2016;133(16):1605-20. doi: 10.1161/CIRCULATIONAHA.114.008729, PMID 27142605.
14. Ajay VS, Prabhakaran D. Coronary heart disease in Indians: Implications of the INTERHEART study. Indian J Med Res. 2010 Nov;132:561-6. doi: 10.4103/09715916.73396, PMID 21150008.

15. Balady GJ, Williams MA, Ades PA, Bittner V, Comoss P, Foody JM, et al. American Heart Association Exercise, Cardiac Rehabilitation, and Prevention Committee, the Council on Clinical Cardiology, American Heart Association Council on Cardiovascular Nursing, American Heart Association Council on Epidemiology and Prevention, American Heart Association Council on Nutrition, Physical Activity, and Metabolism, American Association of Cardiovascular and Pulmonary Rehabilitation. Core components of cardiac rehabilitation/ secondary prevention programs: 2007 update: A scientific statement from the American Heart Association Exercise, Cardiac Rehabilitation, and Prevention Committee, the Council on Clinical Cardiology; the Councils on Cardiovascular Nursing, Epidemiology and Prevention, and Nutrition, Physical Activity, and Metabolism; and the American Association of Cardiovascular and Pulmonary Rehabilitation. Circulation. 2007;115(20):2675-82. doi: 10.1161/ CIRCULATIONAHA.106.180945, PMID 17513578.

16. Fox K. Stable angina pectoris 2006. Compendium of abridged ESC guidelines Berlin: Springer Healthcare Ltd. 2011; 2011. p. 81-93.

17. NICE MI. Secondary prevention. Secondary prevention in primary and secondary care for patients following a myocardial infarction. NICE Guidel. 2013 Nov

18. Beaglehole R, Epping-Jordan J, Patel V, Chopra M, Ebrahim S, Kidd M, et al. Improving the prevention and management of chronic disease in low-income and middle-income countries: A priority for primary health care. Lancet. 2008;372(9642):940-9. doi: 10.1016/S0140-6736(08)61404-X, PMID 18790317.

19. Padmavati S. Epidemiology of cardiovascular disease in India. I. Rheumatic heart disease. Circulation. 1962 Apr;25(4):703-10. doi: 10.1161/01.cir.25.4.703 PMID 14483096

20. Sandozi T, Nausheen. Drug utilization study in ischemic heart diseases associated with diabetes and hypertension. Int J Pharm Biol Sci. 2010;1(3):1-4.

21. Jhaveri BN, Patel TK, Barvaliya MJ, Tripathi CB. Drug utilization pattern and pharmacoeconomic analysis in geriatric medical in-patients of a tertiary care hospital of India. J Pharmacol Pharmacother. 2014;5(1):15-20. doi: 10.4103/0976500X.124411, PMID 24554905.

22. Jyothi K, Saleem TSM, Vineela L, Gopinath C, Reedy K. A retrospective drug utilization study of antiplatelet drugs in patients with ischemic heart disease international journal of medical, health, biomedical, bioengineering and pharmaceutical. Engineering. 2015;9:7.

Article History: Received: 11-10-2021; Revised: 23-11-2021; Accepted: 19-01-2022

Cite this article: Vyas S, Dagar W, Dhanawat M, Manzoor S, Gupta S, Das R, Mehta DK. Drug Utilization Analysis of Anticoagulant and Antiplatelet Drugs in Cardiology Department of a Tertiary Care Hospital. J Young Pharm. 2022;14(1):122-5. 